\title{
Bony periosteum-covered iliac crest plug transplantation for severe osteochondral lesions of the talus: a modified mosaicplasty procedure
}

\author{
André Leumann • Victor Valderrabano - Martin Wiewiorski • \\ Alexej Barg • Beat Hintermann · Geert Pagenstert
}

Received: 24 January 2013/ Accepted: 2 July 2013/Published online: 13 July 2013

(C) Springer-Verlag Berlin Heidelberg 2013

\begin{abstract}
Purpose This study reports first evidence of a modified procedure for osteochondral autologous transplantation where bony periosteum-covered plugs are harvested at the iliac crest and transplanted into the talar osteochondral lesion.

Methods Thirteen out of 14 patients, average age 39.6 (SD 14.4) years, were followed clinically and radiographically for a median of 25 (24-28) months (minimal followup, 24 months).

Results For these 13 patients, the American Orthopaedic Foot and Ankle Society hindfoot score increased from 47 (SD 11) points pre-operatively, to 81 (SD 14) points postoperatively $(p<0.0001)$. The average pain score decreased from 6.6 (SD 1.3) points pre-operatively, to 1.4 (SD 1.9) points postoperatively $(p<0.0001)$. Seven patients returned to sports activity. Radiographically good plug osteointegration was observed in nine out of 11 ankles. Follow-up arthroscopy showed fibrous cartilage in four ankles, periosteum hypertrophy in five ankles, and partial or total missing of coverage of the bone in three ankles. Three revision surgeries had to be performed.

Conclusions This modified mosaicplasty might be recommended for severe and recurrent osteochondral lesions of the talus and may lead to restoration of the subchondral bone stock, formation of fibro-cartilage, and stable joint function.

Level of evidence IV.
\end{abstract}

\footnotetext{
A. Leumann $(\bowtie) \cdot V$. Valderrabano $\cdot$ M. Wiewiorski

A. Barg · B. Hintermann · G. Pagenstert

Orthopaedic Department, University Hospital of Basel,

Spitalstr. 21, 4031 Basel, Switzerland

e-mail: aleumann@uhbs.ch
}

Keywords Osteochondral - Talus · Mosaicplasty · Iliac crest $\cdot$ Arthroscopy $\cdot$ SPECT-CT

\section{Introduction}

Osteochondral lesions (OCL) of the talus are more frequent than previously estimated and affect young, sports active patients [38]. For OCL treatment, a variety of techniques are known, primarily adapted from techniques used to treat cartilage lesions of the knee joint. For talus OCL, treatment results lack evidence and consistency [34]. Treatment strategies may address three levels: (I) the chondral level; (II) the osseous level; (III) the osteochondral level as a combination of the chondral and the osseous level. The osseous component of OCL is suspected to be the main origin of pain as cartilage is aneural, while the osseous level has an important impact on ongoing joint degeneration [9]. The only autologous osteochondral therapy that reconstructs both layers and results in intrinsic stability between cartilage and bone (treatment strategy III) is the osteochondral autologous transplantation or so called mosaicplasty [12, 32]. With this technique, osteochondral plug cylinders are harvested at the knee joint and transplanted to the ankle joint. Although high success rates of up to $94 \%$ have been reported, recent studies suggested significant midterm donor-site morbidity at the previously uninjured knee joint [29, 31, 35].

On the search for an alternative method that addresses both the osseous and chondral levels and provides intrinsic osteochondral stability without harming another joint, a modified mosaicplasty procedure was developed for severe and recurrent talus OCL: bony periosteum-covered iliac crest plug transplantation. The bone is needed to fill the osseous defect and cyst formation. The periosteum was identified to have pluripotent stem cells with the capacity of differentiating 
into chondrocytes and fibro-cartilage [8, 26]. The periosteum is fixed to its underlying cortical bone on cellular and extracellular levels, thus providing intrinsic mechanical stability and biological interaction (e.g. vascular supply, cell interactions) $[18,30]$.

Therefore, the aim of this prospective study was to document the clinical and radiographic outcomes of patients in which bony periosteum-covered plugs were transplanted from the iliac crest to the ankle joint for treatment of severe and recurrent talus OCL. The hypothesis was that adequate results can be achieved in severe and recurrent talus OCL with this modified technique without creating an articular donorsite morbidity.

\section{Materials and methods}

A prospective observational study was carried out at the University Hospital of Basel, Switzerland, on all patients undergoing modified mosaicplasty. There were three female and 11 male patients with a mean age of 39.6 (SD 14.4) years. Inclusion criteria were unilateral, painful, and radiologically verified severe or recurrent OCL of the talus of Berndt/Harty/ Loomer grade 3-5 with a large involvement of the subchondral bone [4, 24]. Exclusion criteria were OCL lesion size $<1.5 \mathrm{~cm}^{2}$ or depth of lesion $<0.8 \mathrm{~cm}$, diabetes mellitus, neurological and mental disorders, follow-up time shorter than 2 years, osteochondral lesions grade 1 or 2 , varus or valgus malalignment, and osteochondral lesions that could be treated with retrograde drilling, microfracturing, or autologous chondrocyte transplantation. The last criterion was added to exclude patients who could be treated with a less invasive procedure. Localization of the lesions was medial, lateral, and central in 10, three, and one ankles, respectively. Symptoms included pain, joint blocking, and swelling and persisted for a median of $10.0(0.5-30)$ years. Aetiologically, trauma was historical in 13 out of 14 ankles: ankle or talus fracture in six ankles, sprains and persistent chronic ankle instability in six ankles, and direct contusion in one ankle. Ten patients had between one and five surgeries before undergoing the modified mosaicplasty procedure: arthroscopy (8), osteosynthesis (5), implant removal (4), retrograde drilling (4), ligament reconstruction (4), microfracturing (1), and cancellous bone grafting (1). Thirteen patients were available for clinical and radiological follow-up at 25 (24-28) months, wherefrom two patients agreed for clinical follow-up examination only. One patient was lost for follow-up due to change of address.

\section{Surgical technique}

Procedure was performed as a one-stage procedure. Medial malleolus osteotomy was necessary in nine ankles to access the joint (Fig. 1a). The lateral joint was accessed through an anterolateral approach in three ankles. The lesion was identified and excised with a mosaicplasty hollow drill [12] (Fig. 1b; Synthes Inc., Oberdorf, Switzerland). Lesion size averaged $173 \mathrm{~mm}^{2}$ (SD $39 \mathrm{~mm}^{2}$ ). A depth of 15-20 mm was necessary to excise all the involved bone. The anterior iliac crest was then accessed through an incision directly overlying the harvesting area, and the iliac crest was exploited without harming the periosteal layer (Fig. 1c). It was possible to drill the plugs at the edge of the iliac crest to mimic the shape of the talar edge [23]. With caution not to harm the periosteum, the harvested plugs were inserted into the drilled holes of the talus with the periosteum layer slightly below the cartilage level. Ankle joint motion was tested for smooth function before the joint was closed (Fig. 1d). If medial or lateral ankle instability was found, the ligaments were reconstructed in the same procedure. This was necessary in six ankles. Postoperative care consisted of partial weight bearing for 6 weeks and early functional rehabilitation including lymphatic drainage, training of range of motion, and sensorimotor training, in later stages also strength training, and instructions for return to sports as tolerated by the patients.

In nine ankles, re-arthroscopy or arthrotomy was performed at latest follow-up. Direct visual inspection of the lesion, probe indentation of the cartilage to assess cartilage quality, and examination and probe indentation of the surrounding and the opposing cartilage was performed.

\section{Clinical examination}

Patients rated their pain on a visual analogue scale (VAS) of 0 points (no pain) to 10 points (maximal pain) [14]. They also indicated their satisfaction with the procedure (modified Coughlin rating for category scale: very satisfied, satisfied, partially satisfied, not satisfied) [7]. The American Orthopaedic Foot and Ankle Society (AOFAS) hindfoot score was calculated [0-100 (maximal value) points divided in pain (maximal 40 pts.), function (maximal 50 pts.), and alignment (maximal 10 pts.)] [16]. Each patient's sports activity level was documented pre-operatively and during the latest follow-up using the following score: grade 0 , none; grade 1 , moderate; grade 2, normal; grade 3, high; and grade 4, elite [36].

\section{Radiographic evaluation}

Weight bearing radiographs were scored for OCL after Berndt and Harty/Loomer: grade 1, subchondral compression; grade 2, partially avulsed fragment; grade 3, detached but not displaced fragment; grade 4, displaced fragments; grade 5, subchondral cyst [4, 24]. Magnetic resonance imaging (MRI) in nine ankles and single photon emission 

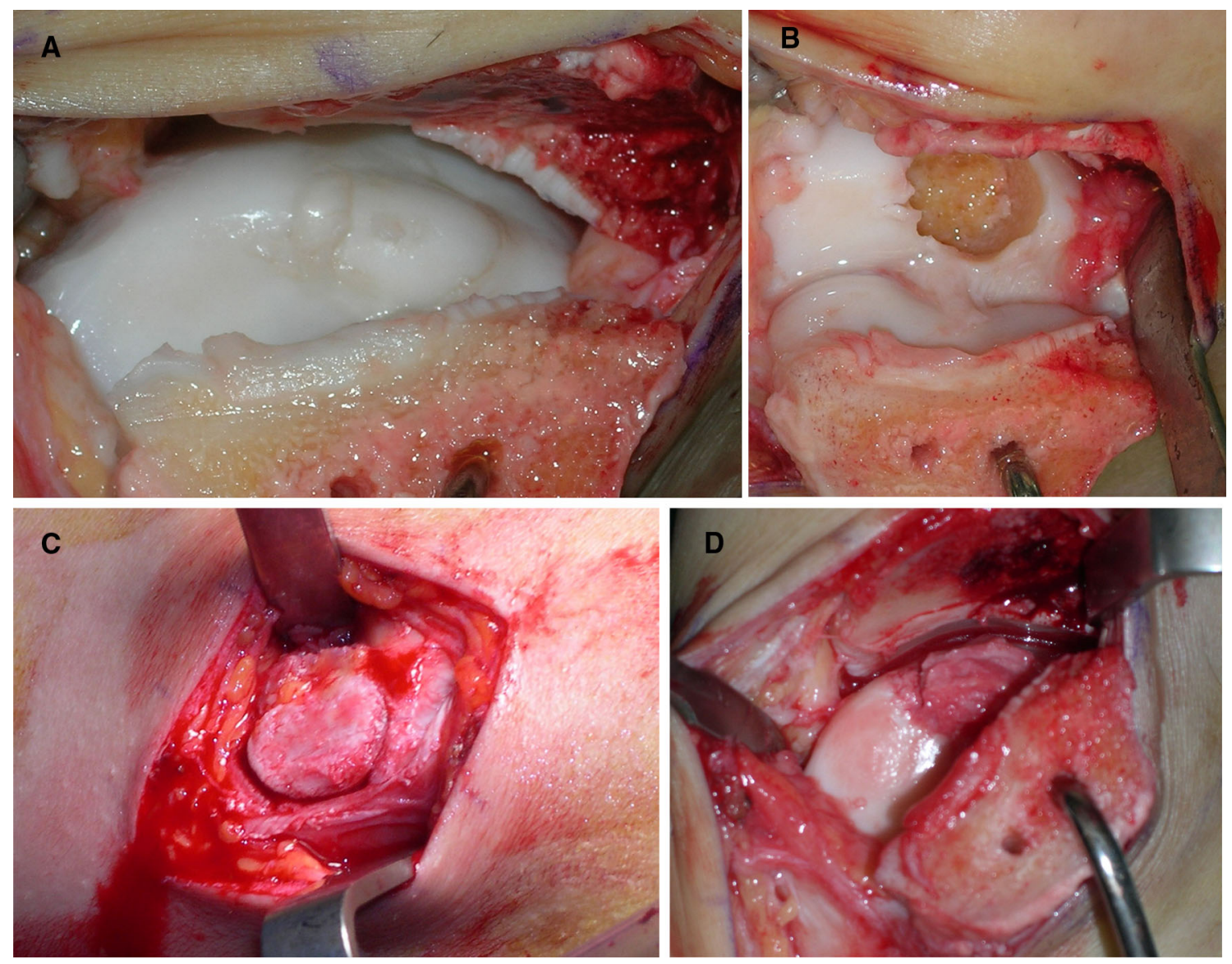

Fig. 1 Modified mosaicplasty procedure. The osteochondral lesion of the talus (a) was excised with a hollow drill (b). A plug was harvested at the iliac crest (c) and inserted using press-fit technique into the talar lesion (d)

computed tomography-computed tomography (SPECTCT) - in five ankles were recorded and scored after Taranow: grade 1, subchondral compression; grade 2, subchondral cyst; grade 3, detached but not displaced fragments; grade 4, displaced fragments [22, 33]. MRI consisted of native and gadolinium-enhanced 1.5 T MRI (Espree, Siemens, Germany) with T1, T2, and TIRM weighting. SPECT-CT (Symbia T2, Siemens, Germany), represents a digital fusion of $3 \mathrm{D}$ bone scintigraphy (SPECT) and a computed tomography scan (CT) that are recorded on the same machine in a fixed foot position [28].

\section{Ethics}

The study was conducted in accordance with the ethical standards of the responsible committee on human experimentation and with the Helsinki Declaration of 1975, as revised in 2000. The protocol was approved by the Ethics Committee of the University of Basel (Reference Number 49/08), Switzerland. All participants provided informed written consent prior to surgery and study.
Statistical analysis

A Kolmogorov-Smirnov normality test was performed to verify whether data were normally distributed. Normally distributed data are presented as mean (standard deviation). Non-normal data are presented as median (range). Student's $t$ tests and Mann-Whitney rank sum tests were used for data comparison in normally and non-normally distributed data, respectively. A $p$ value $\leq 0.05$ was considered to be statistically significant. Data were analysed using SPSS v16.0 (SPSS Inc., Chicago, IL, USA) and SigmaPlot 2004 (Systat Software Inc., San Jose, CA, USA).

\section{Results}

Clinical results

A substantial pain relief in all the patients was found [VAS, 6.6 (SD 1.3) pts pre-operatively to 1.4 (SD 1.9) pts postoperatively $(p<0.001)]$. Along with it, hindfoot function 
improved significantly [AOFAS-hindfoot score, 47.2 (SD 11.1) pts pre-operatively to 81.3 (SD 14.0) pts postoperatively $(p<0.001)$ ] (Fig. 2).

Before injury or onset of symptoms, the cohort showed a high activity in sports: five patients were elite athletes (level 4), three patients did sports more than $5 \mathrm{~h} /$ week (level 3), one patient 1-5 h/week (level 2), and five patients did sports once/week (level 1), with four of them being heavy workers. Sports included were soccer (5), volleyball (2), hiking (2), general sports (2), running, boxing, tennis, horse riding, gymnastics, and strength training (one each). At follow-up, seven patients returned to sports activity, with three reaching their pre-injury level.

For the iliac crest donor site, none of the patients reported any complaints of pain or tenderness during the postoperative rehabilitation course or at follow-up. No scarring problems or signs for wound or deep infection were found.

At final follow-up, nine patients were very satisfied, two patients satisfied, and two patients dissatisfied. Ten patients would agree to undergo the same procedure again.

\section{Radiographic results}

Pre-operative radiologic evaluation showed grade 3 in two ankles, grade 4 in three ankles, and grade 5 in nine ankles for Berndt/Harty/Loomer classification [4, 24] (Fig. 3a). All lesions were accompanied with focal bone marrow oedema on the MRI (nine ankles) or focal scintigraphic activity (five ankles) in the SPECT-CT (Fig. 3b). The subchondral bone plate was disrupted in all 14 ankles, subchondral bone defects or cyst formation was found in 11 ankles, and subchondral sclerosis was found in all 14 ankles.

Follow-up examination with the SPECT-CT was completed on 11 ankles. Stable plug incorporation was found in

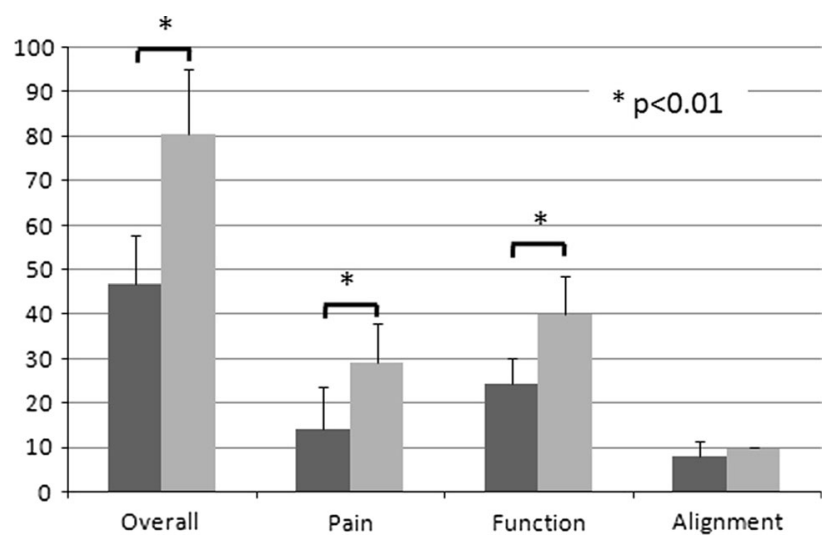

Fig. 2 AOFAS ankle score. Pre-operative (black) and follow-up (grey) results for the overall AOFAS ankle score and its subdivisions; pain, function and alignment $(* p<0.01)$ nine ankles, and two ankles showed missing plug integration. The subchondral bone plate was without disruption in six ankles, and in five ankles, disruptions were found, respectively. In nine ankles, persistent scintigraphic activity was found (Fig. 3c). Cyst recurrence was found in seven ankles, of them in five ankles, they were smaller than preoperatively; in two ankles, they had the same size. In four ankles, no cysts were found. Two ankles showed kissing lesions and at least compartmental, ongoing joint degeneration (subchondral sclerosis, and joint space narrowing).

Arthroscopic results

Follow-up arthroscopy or arthrotomy was performed in nine ankles. Indications for surgery were hardware removal at osteotomy site (arthroscopy, six ankles) or revision
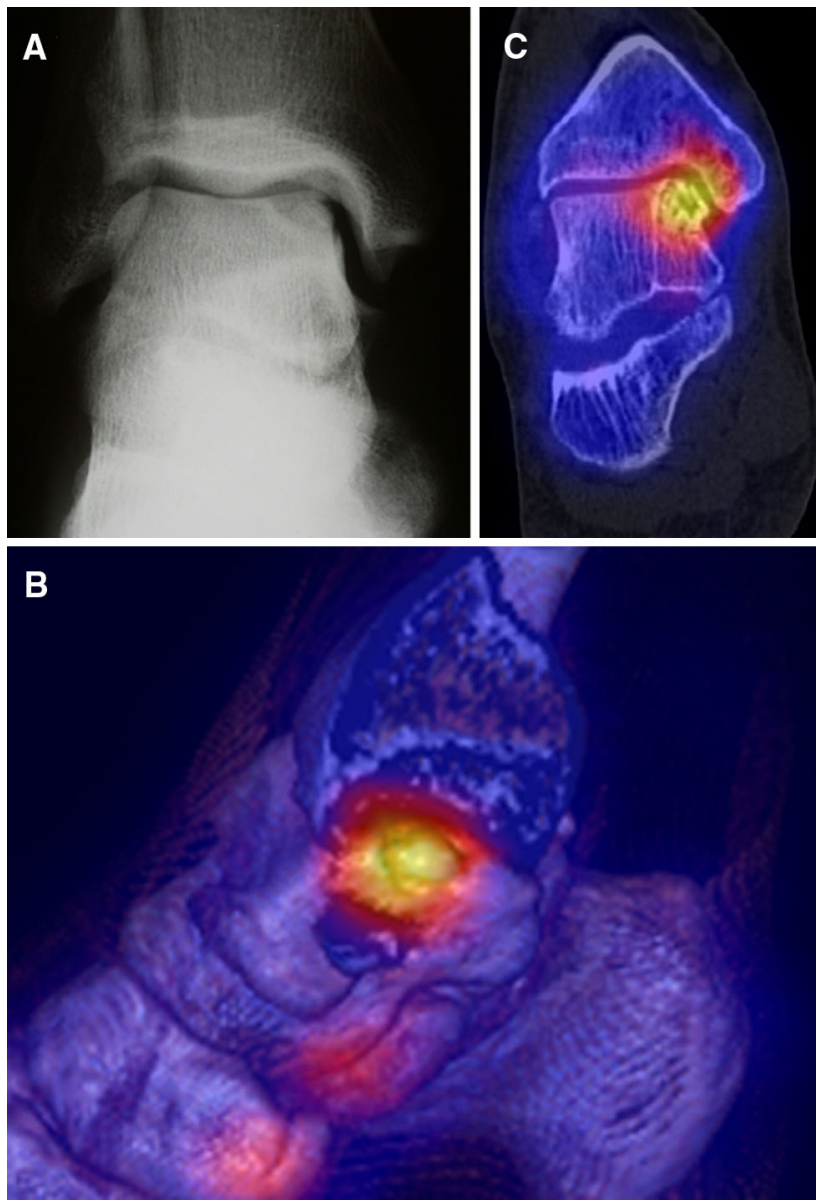

Fig. 3 Radiographic documentation. 21-year-old semi-professional soccer player 15 months after direct contusion injury and 12 months after arthroscopic microfracturing. Pre-operative weight-bearing $\mathrm{X}$-ray (anterior-posterior) showed a Berndt Harty grade 4 (a). The pre-operative $3 \mathrm{D}$ reconstructed SPECT-CT revealed the lesion and its focal scintigraphic activity (b). Follow-up SPECT-CT (c) confirmed good plug integration with a congruent subchondral bone plate integrity, despite some scintigraphic activity remaining. AOFAS ankle score at follow-up: 97 points 
surgery (arthrotomy, three ankles). Total or partial coverage with fibrous cartilage was found in four ankles (Fig. 4a), periosteum hypertrophy in four ankles (Fig. 4b), and partial or total missing coverage of the bone in three ankles. The surrounding cartilage showed no signs of ongoing cartilage degeneration or formation of a kissing lesion except for the revision cases. Open revision surgery was necessary in three ankles that were rated clinically as poor results. Of these, two graft loosenings were found. One had radiosynoviorthesis after the plug implantation due to a villonodular synovitis that was found at the time of the implantation procedure. The other was a result of technical failure. The last case was considered to have a borderline indication due to the presence of early signs of osteoarthritis and failed to show success. It was therefore converted to a total ankle replacement [13].

\section{Discussion}

The most important finding of the present study was that a new modified mosaicplasty procedure (osteoperiosteal autologous transplantation) with plug transplantation from the iliac crest to the ankle joint allowed excellent to satisfying results in $85 \%$ for treatment of severe and recurrent OCL of the talus for a reported minimal follow-up of 2 years. In detail, of the 13 patients available for follow-up, three showed excellent results, four patients showed good and another four satisfying results. A poor result was found in two patients. Overall, three major revision surgeries were indicated after the modified mosaicplasty.

An average AOFAS ankle score of 80.1 points was documented. Although other studies report success rates of 90-100 \% [12, 21] for the "classic" mosaicplasty, our results are consistent with studies reported by Assenmacher et al. [2] or Al-Shaikh et al. [1] who reported AOFAS ankle scores of 80.2 points and 88 points, respectively, with a shorter follow-up of 9.3 and 16 months, respectively, though but both studies excluded recurrent cases. Longer follow-up results for the "classic" mosaicplasty were reported by Valderrabano et al. [35] and recently by Imhoff et al. [15]. They reported of an average AOFAS ankle score of 80.2 and 78.0 points for a follow-up time of 72 and 84 months, respectively $[15,35]$. In a subgroup of nine patients who had one surgical intervention before (debridment and drilling), Imhoff et al. [15] found an AOFAS ankle score at follow-up of 62 points what would be rated as poor in our study. Only Kreuz et al. [20] reported on a series of osteochondral plug transplantations from the malleolar joint facet of the talus to the edge of the talocrural joint for recurrent, previously arthroscopically treated OCL of the ankle. In 35 patients, they found an increase in the AOFAS ankle score of 54-89 points after 49-month
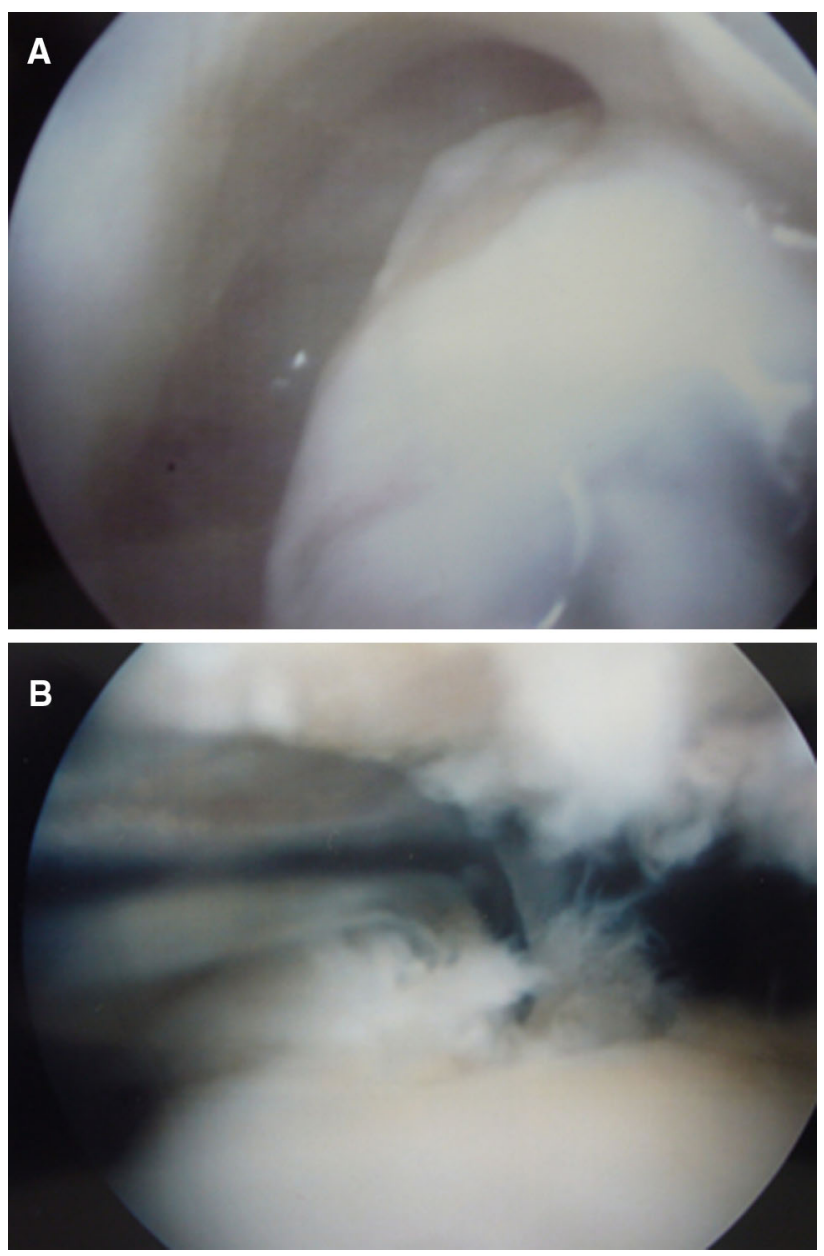

Fig. 4 Follow-up arthroscopy. Follow-up arthroscopy showing fibrous cartilage (a) in one patient and periosteum hypertrophy in another patient (b)

follow-up [20]. Our study reports a comparable increase of 43 points from 47 to 80 points. The high subjective patient satisfaction underlines that patients experienced a significant benefit through the procedure.

A main difference of severe OCL of the talus to the knee is the inclusion of the subchondral bone. Bone sclerosis, fragment displacement, and cyst formation are very frequent in talar OCL [13]. In our series, these factors were found in all patients. Based on our interpretation, many of the possible treatment procedures such as autologous chondrocyte implantation (ACI) or microfracture are not as applicable for the ankle as for the knee joint as they do not address the osseous level sufficiently enough $[11,17]$. The integrity and stability of the subchondral bone plate seems to play an important role in the pathogenesis of OCL of the ankle. One theory of subchondral cyst formation refers to the recurrent pumping of joint fluid through a disruption of the cartilage and subchondral bone plate into the subchondral bone with every joint motion leading to an unstable cartilage cover $[35,37]$. The bone seems to play 
an important role not only in the pathogenesis of OCL of the ankle, but also in pain nociception [12]. Although it is unclear, if pain originates from subchondral bone, ligaments, or synovitis, radiographic findings on the SPECTCT of focal scintigraphic activity or bone marrow oedema on MRI recordings may suggest that the subchondral bone has an important role as a pain source [5]. Therefore, we concur with Gross [11] that severe and recurrent OCL with deep involvement of subchondral bone benefit from reconstruction with a stable transplant addressing subchondral bone, cartilage, and its intrinsic stability through a stable connection of both layers.

The "classic" mosaicplasty procedure described by Hangody et al. with osteochondral plug transplantation from the knee joint to the talus initially showed excellent results with short- to midterm survival in up to $100 \%$ and good and excellent outcomes in up to $94 \%[2,12]$. However, Reddy et al. [31] reported significant donor-site morbidity in four out of 11 patients including patellar instability and ongoing joint degeneration. Recently, it has been shown that knee-to-talus mosaicplasty causes significant radiographic knee joint morbidity and clinical knee symptoms in $58 \%$ [35]. Additionally, several authors reported restricted results at the ankle joint site including cyst recurrence $[25,35]$. Why should an asymptomatic joint be harmed if it resulted only in a moderate outcome? A benefit of this modified procedure is that no significant donor-site morbidity occurs at the iliac crest.

It is well accepted that periosteum has the potential to develop into fibro-cartilage [8]. Several studies have reported on the chondrogenic potential of periosteum in vitro and in vivo. Bahrami et al. [3] identified osteoprogenitor cells in 18-month-old calves that differentiate into chondrocytes in vitro. Caplan [6] suspected pluripotent stem cells contained within the periosteum to be responsible for the chondrogenesis. O'Driscoll et al. [26, 27] described that chondrogenic potential depended on the cell count of the cambium layer of the periosteum and on the patient's age. So far, no study has addressed the potential of periosteum to differentiate into cartilage in a clinical study. Comparison of clinical outcome between fibro-cartilage (e.g. by microfracturing) or hyalinelike cartilage (e.g. by ACI) formation evidenced no significant clinical or radiographic differences in midterm follow-up examinations in the knee or ankle joint $[10,17]$. For the ankle joint, Gobbi et al. [10] found no differences in the AOFAS ankle score after 53 months for chondroplasty (synonymous for abrasio; regeneration with fibro-cartilage), microfracture (regeneration with fibro-cartilage), or autologous osteochondral transplantation (mosaicplasty; regeneration with hyaline cartilage) in a prospective randomized trial.

For follow-up examination, radiographic evaluation by SPECT-CT was possible in 11 patients and re-arthroscopy or arthrotomy in nine patients. Three main issues were documented at follow-up: (I) Nine ankles had stable plug integration. A vital and stable subchondral bone stock is important for every type of joint reconstruction. (II) Several patients reported a significant clinical improvement after hardware removal. As a consequence, our patients who underwent this procedure were informed pre-operatively that an additional intervention may be necessary. (III) Inspection of the lesion site showed fibro-cartilage formation in four cases and periosteum hypertrophy in four cases. Periosteal hypertrophy within a synovial joint has been well reported from the first generation ACI technique where the chondrocyte suspension was covered by a periosteal layer [19]. Shaving of the hypertrophic tissue lead to a significant clinical improvement.

This study has several limitations including small patient number and the level of evidence (level 4). To our knowledge, only one study by Gobbi et al. [10] reached a high level of evidence (level II). The comparison of different studies on talus OCL is difficult as talus OCL may show high heterogeneity (e.g. lesion size and type, patient age, duration of symptoms, previously performed symptoms, and others). These factors must be seen as confounding factors and considered for the interpretation of the results. Future studies need to address different techniques in prospective, randomized trials in order to be able to understand advantages and disadvantages of different techniques.

Revision surgeries for talus OCL remain frequent although good results were reported on different techniques. Typically, these revision cases were referred to our clinic. Here, this new modified mosaicplasty technique is a final approach as an alternative to ankle joint replacement or arthrodesis. Although the reported results are midterm, the reported clinical and radiographic outcomes under these circumstances are promising and encouraging. Additionally to clinical follow-up examination, radiographic and arthroscopic follow-up examination was possible. However, due to ethical reasons, regular histologic analysis for cartilage quality was not possible.

\section{Conclusion}

In conclusion, this modified mosaicplasty procedure with plug transplantation from the iliac crest to the ankle joint offers a new, joint-preserving alternative surgical option for recurrent or severe osteochondral lesions with a highly reproducible and satisfying outcome. This study showed that restoration of the subchondral bone block, formation of fibrocartilage, and stable joint function can be achieved.

Acknowledgments The authors acknowledge the Swiss Federal Council of Sports (Magglingen, Switzerland) for the financial support of this study within the research concept "Sport and Motion". 
Conflict of interest The authors declare that they have no conflict of interest.

\section{References}

1. Al Shaikh RA, Chou LB, Mann JA, Dreeben SM, Prieskorn D (2002) Autologous osteochondral grafting for talar cartilage defects. Foot Ankle Int 23:381-389

2. Assenmacher JA, Kelikian AS, Gottlob C, Kodros S (2001) Arthroscopically assisted autologous osteochondral transplantation for osteochondral lesions of the talar dome: an MRI and clinical follow-up study. Foot Ankle Int 22:544-551

3. Bahrami S, Stratmann U, Wiesmann HP, Mokrys K, Bruckner P, Szuwart T (2000) Periosteally derived osteoblast-like cells differentiate into chondrocytes in suspension culture in agarose. Anat Rec 259:124-130

4. Berndt AL, Harty M (1959) Transchondral fractures (osteochondritis dissecans) of the talus. J Bone Joint Surg Am 41:988-1020

5. Buck FM, Hoffmann A, Hofer B, Pfirrmann CW, Allgayer B (2009) Chronic medial knee pain without history of prior trauma: correlation of pain at rest and during exercise using bone scintigraphy and MR imaging. Skeletal Radiol 38:339-347

6. Caplan AI (1990) Cartilage begets bone versus endochondral myelopoiesis. Clin Orthop Relat Res 261:257-267

7. Coughlin M (1990) Arthrodesis of the first metatarsophalangeal joint with mini-fragment plate fixation. Orthopedics 13:1037-1044

8. Fang J, Hall BK (1997) Chondrogenic cell differentiation from membrane bone periostea. Anat Embryol (Berl) 196:349-362

9. Ferkel RD, Zanotti RM, Komenda GA, Sgaglione NA, Cheng MS, Applegate GR, Dopirak RM (2008) Arthroscopic treatment of chronic osteochondral lesions of the talus: long-term results. Am J Sports Med 36:1750-1762

10. Gobbi A, Francisco RA, Lubowitz JH, Allegra F, Canata G (2006) Osteochondral lesions of the talus: randomized controlled trial comparing chondroplasty, microfracture, and osteochondral autograft transplantation. Arthroscopy 22:1085-1092

11. Gross AE (2003) Cartilage resurfacing: filling defects. J Arthroplast 18:14-17

12. Hangody L, Kish G, Modis L, Szerb I, Gaspar L, Dioszegi Z, Kendik Z (2001) Mosaicplasty for the treatment of osteochondritis dissecans of the talus: two to seven year results in 36 patients. Foot Ankle Int 22:552-558

13. Hintermann B, Valderrabano V, Dereymaeker G, Dick W (2004) The HINTEGRA ankle: rationale and short-term results of 122 consecutive ankles. Clin Orthop Relat Res 424:57-68

14. Huskisson EC (1974) Measurement of pain. Lancet 2:1127-1131

15. Imhoff AB, Paul J, Ottinger B, Wortler K, Lammle L, Spang J, Hinterwimmer S (2011) Osteochondral transplantation of the talus: long-term clinical and magnetic resonance imaging evaluation. Am J Sports Med 39:1487-1493

16. Kitaoka HB, Alexander IJ, Adelaar RS, Nunley JA, Myerson MS, Sanders M (1994) Clinical rating systems for the ankle-hindfoot, midfoot, hallux, and lesser toes. Foot Ankle Int 15:349-353

17. Knutsen G, Drogset JO, Engebretsen L, Grontvedt T, Isaksen V, Ludvigsen TC, Roberts S, Solheim E, Strand T, Johansen O (2007) A randomized trial comparing autologous chondrocyte implantation with microfracture. Findings at five years. J Bone Joint Surg Am 89:2105-2112

18. Kojimoto H, Yasui N, Goto T, Matsuda S, Shimomura Y (1988) Bone lengthening in rabbits by callus distraction. The role of periosteum and endosteum. J Bone Joint Surg Br 70:543-549

19. Kreuz PC, Steinwachs M, Erggelet C, Krause SJ, Ossendorf C, Maier D, Ghanem N, Uhl M, Haag M (2007) Classification of graft hypertrophy after autologous chondrocyte implantation of full-thickness chondral defects in the knee. Osteoarthritis Cartilage 15:1339-1347

20. Kreuz PC, Steinwachs M, Erggelet C, Lahm A, Henle P, Niemeyer P (2006) Mosaicplasty with autogenous talar autograft for osteochondral lesions of the talus after failed primary arthroscopic management: a prospective study with a 4-year follow-up. Am J Sports Med 34:55-63

21. Lee CH, Chao KH, Huang GS, Wu SS (2003) Osteochondral autografts for osteochondritis dissecans of the talus. Foot Ankle Int 24:815-822

22. Leumann A, Valderrabano V, Plaass C, Rasch H, Studler U, Hintermann B, Pagenstert GI (2011) A novel imaging method for osteochondral lesions of the talus-comparison of SPECT-CT with MRI. Am J Sports Med 39:1095-1101

23. Leumann A, Wiewiorski M, Egelhof T, Rasch H, Magerkurth O, Candrian C, Schaefer DJ, Martin I, Jakob M, Valderrabano V (2009) Radiographic evaluation of frontal talar edge configuration for osteochondral plug transplantation. Clin Anat 22:261-266

24. Loomer R, Fisher C, Lloyd-Smith R, Sisler J, Cooney T (1993) Osteochondral lesions of the talus. Am J Sports Med 21:13-19

25. Nakagawa Y, Suzuki T, Matsusue Y, Kuroki H, Mizuno Y, Nakamura T (2005) Bony lesion recurrence after mosaicplasty for osteochondritis dissecans of the talus. Arthroscopy 21:630

26. O'Driscoll SW, Fitzsimmons JS (2001) The role of periosteum in cartilage repair. Clin Orthop Relat Res 391:S190-S207

27. O'Driscoll SW, Saris DB, Ito Y, Fitzimmons JS (2001) The chondrogenic potential of periosteum decreases with age. J Orthop Res 19:95-103

28. Pagenstert GI, Barg A, Leumann AG, Rasch H, Muller-Brand J, Hintermann B, Valderrabano V (2009) SPECT-CT imaging in degenerative joint disease of the foot and ankle. J Bone Joint Surg Br 91:1191-1196

29. Paul J, Sagstetter A, Kriner M, Imhoff AB, Spang J, Hinterwimmer S (2009) Donor-site morbidity after osteochondral autologous transplantation for lesions of the talus. J Bone Joint Surg Am 91:1683-1688

30. Popowics TW, Zhu Z, Herring SW (2002) Mechanical properties of the periosteum in the pig, Sus scrofa. Arch Oral Biol 47:733-741

31. Reddy S, Pedowitz DI, Parekh SG, Sennett BJ, Okereke E (2007) The morbidity associated with osteochondral harvest from asymptomatic knees for the treatment of osteochondral lesions of the talus. Am J Sports Med 35:80-85

32. Scranton PE Jr, Frey CC, Feder KS (2006) Outcome of osteochondral autograft transplantation for type- $\mathrm{V}$ cystic osteochondral lesions of the talus. J Bone Joint Surg Br 88:614-619

33. Taranow WS, Bisignani GA, Towers JD, Conti SF (1999) Retrograde drilling of osteochondral lesions of the medial talar dome. Foot Ankle Int 20:474-480

34. Valderrabano V, Leumann A (2008) Osteochondral lesions of the talus. In: Wright JG (ed) Evidence-based orthopaedics. Saunders WB Co., Philadelphia, pp 462-472

35. Valderrabano V, Leumann A, Rasch H, Egelhof T, Hintermann B, Pagenstert G (2009) Knee-to-ankle mosaicplasty for the treatment of osteochondral lesions of the ankle joint. Am J Sports Med 37(Suppl 1):105S-111S

36. Valderrabano V, Pagenstert G, Horisberger M, Knupp M, Hintermann B (2006) Sports and recreation activity of ankle arthritis patients before and after total ankle replacement. Am J Sports Med 34:993-999

37. van Dijk CN, Reilingh ML, Zengerink M, van Bergen CJ (2010) Osteochondral defects in the ankle: why painful? Knee Surg Sports Traumatol Arthrosc 18:570-580

38. Verhagen RA, Struijs PA, Bossuyt PM, van Dijk CN (2003) Systematic review of treatment strategies for osteochondral defects of the talar dome. Foot Ankle Clin 8:233-2ix 